\title{
Use of Internet of things to assess KPI in the transport logistics service
}

\author{
Dubolazov V.A. \\ Institute of Industrial \\ Management, Economics and \\ Trade \\ Peter the Great \\ St.Petersburg Polytechnic \\ University Saint- \\ Petersburg, Russia \\ dubolazov@kafedrapik.ru
}

\author{
Shchelkonogov A.A. \\ Institute of Industrial Management, \\ Economics and Trade \\ Peter the Great St.Petersburg \\ Polytechnic University \\ Saint-Petersburg, Russia \\ epsilan@mail.ru
}

\author{
Temirgaliev E.R. \\ Institute of Industrial Management, \\ Economics and Trade \\ Peter the Great St.Petersburg \\ Polytechnic University Saint- \\ Petersburg, Russia \\ temirgaliev@kafedrapik.ru
}

\begin{abstract}
Analysis of research in the field of Key Performance Indicators for assessing logistics showed the importance of accounting and quality control of logistics services. As part of the global digitization of business processes, including controlling, the development of digital logistics becomes more popular. When implementing measures to assess the efficiency of transport and logistics services, it is necessary to apply technologies Internet of Things (IoT) and technologies Radio Frequency Identification (RFID). As a result, the introduction of the above technologies can significantly improve the data collection process and increase the supply chain visibility. The article considers the use of digital technologies in transport logistics and their impact on the quality of logistics services, describes the contemporary problems that impede the implementation. A list of performance indicators of transport and logistics services can be used as a template for building a balanced scorecard of company's logistics. The use of Internet of Things provides great opportunities to create a transparent logistics network, taking advantage of the growing interest in Radio Frequency Identification in transport. The main contribution of this article lies in description use digital technologies in logistics by the example of controlling the transport and logistics services within the framework of the company's balanced scorecard system.
\end{abstract}

Keywords - controlling, Balanced Scorecard (BSC), Key Performance Indicators (KPI), logistics service, transport logistics Internet of things

\section{INTRODUCTION}

Research at the end of the 20th century has shown that the traditional financial assessment of the organization's performance was unsuccessful by the fact that intangible assets of companies accounted for most of the market value of an average firm. In this regard, there is a need for an alternative methodology for evaluating the effectiveness of companies. A tool that can measure effectiveness up to an individual staff member is David Parmenter's Key Performance Indicator System (KPI), which was developed in addition to David Norton and Robert Kaplan's Balanced Scorecard (BSC). Using various indicators, make it possible not only to assess the performance of the organization, but also for monitoring operational activities to improve the efficiency of salary system and motivate staff. However, those companies that adopt a Balanced Scorecard and KPIs are faced with the problem of choosing the most important indicators that can show a complete picture of what is happening in the enterprise and catch tendencies in key areas of its activity.

Thus, the popularity of the KPI tool among a large number of enterprises and simultaneous difficulty of choosing the right metrics only confirm the relevance of the article.

The purpose of the paper is to apply of David Parmenter's Key Performance Indicators as a tool for controlling the activities of the company's transport logistics using modern digital technologies.

\section{MATERIAL AND RESEARCH}

\section{A. Balanced scorecard}

The balanced scorecard (BSC) is the system of strategic goals and metrics that determine the degree of their achievement, which appeared in the late 20th century, as a management and controlling tool for dynamically developing companies.

The key objective of the balanced scorecard system is to transform the company's mission into a system of specific goals and indicators for the most effective organization operating activities of the enterprise. The balanced scorecard transforms strategy into objectives and indicators grouped into four different areas, such as finance, customers, internal business process, training and skills development.

The Balanced Scorecard is the control over the ongoing corporate strategy. For this purpose it is necessary to find the data, establish the necessary values and units of measurement choose the option for adjustment. [4] Balanced scorecard being used by companies to group indicators in such a way that they describe a picture of the process of the entire business or the work of the business unit with first glance at them [5].

\section{B. Key performance Indicators}

As has been said, KPI (Key Performance Indicators) is part of the balanced scorecard system. These are performance indicators of departments or individual employees that contribute to more efficient achievement of strategic goals and allow you to track the effectiveness of each process. However, there are a lot of organizations that implement the balanced scorecard system and wrongly 
accept many company performance indicators as key ones. According to David Parmenter [6] there are three types of performance indicators:

1) Key Result Indicators (KRI);

2) Performance Indicators (PI), Result Indicators (RI);

3) Key Performance Indicators (KPI).

Key Result Indicators illustrate the current state of the company. This is often a superficial, but convenient for shareholders and board members reporting form. However, this type of indicators does not show what has to be done in order to improve the result. Generally, Key Result Indicators cover a long reporting period, including:

1) return of working capital;

2) customer profitability;

3) net profit before tax,

4) job satisfaction;

Performance Indicators (PI), Result Indicators (RI) represent about $80 \%$ of the total number of indicators. Despite the importance of performance indicators, they are not crucial to activity of the company, they are helping departments to relate their results to the company's strategy. Performance indicators are necessarily non-financial and complement KPI as part of a balanced scorecard for the entire enterprise or a separate department. These indicators may include:

1) percent of the increase for key customers;

2) number of complaints from customers;

3) number of overdue supplies for key customers.

Result Indicators represent all the results for the past reporting period (day, week, month) and are a combination of many actions, and therefore do not show what is specifically required to solve the problem. For Result indicators that are not crucial include:

1) net profit on key customers;

2) sales for the past day/week/month;

3) the amount of payment of key customers' claims;

Key Performance Indicators are a set of measures aimed at those aspects of organizational activity that are most important for the current and future success of an organization. There are seven characteristics of KPI:

1) are non-financial measures,

2) are traced regularly with high frequency;

3) are acted on by the CEO and senior management team;

4) clearly indicate what action is required by staff;

5) are measures that tie responsibility down to a team;

6) have a significant impact;

7) encourage appropriate action.

As mentioned above, Key performance indicators are a tool for controlling any business processes, including logistics. It is known that the cost of logistics from the final price of the goods may take a larger share. However, in addition to the elementary logistics costs reduction, other factors should be taken into account, such as the level of logistics services. This criterion allows to increase the loyalty of existing customers of the organization, to attract new cooperation, thereby increasing sales and, accordingly, revenue.

\section{Logistics performance Indicators}

So far, there is no single list of criteria for assessing the effectiveness of logistics among the scientific community. However, Sergeev V.I. and his colleagues [6] include the following indicators among the Performance Indicators and Result Indicators:

- full and operational logistics costs

- satisfaction of customer in relation to the quality of logistics services

- length of logistics cycles

- productivity of infrastructure elements and personnel of the company's logistics efficiency of use of investments in logistics infrastructure.

Lukinsky and Shulzhenko use the same structure of logistic indicators in their work [7]. These indicators are described by the authors as: "Key Performance Indicators of the logistics system are the main measures of resource efficiency in a company for a developed logistics system, which together evaluate the performance of logistics management and are the basis of logistic planning, accounting and control."

Despite the importance of the logistics service, there are still no effective ways to assess its quality, which is explained by a number of features of the service in comparison with the characteristics of the products. These features are:

- The intangibility of the service. It is difficult for service providers to explain and specify specifications for services, and it is also difficult for buyers to evaluate them.

- The buyer is often directly involved in the production of services.

- $\quad$ Services are consumed at the moment when they are produced, i.e. services are not stored or transported.

- The buyer never becomes the owner, purchasing services.

- Service is an activity, and therefore it cannot be tested before the buyer buys it.

It is quite problematic to determine the quality of the logistics service. Often this is characterized by meeting the expectations of consumers of services and their perception of various quality criteria. According to Sergeev V.I. [8], the most important quality measures of service are:

1) reliability - execution "just in time", i.e. in the physical distribution, delivery of the right product at the right time to the right place;

2) reliability of information and financial procedures accompanying physical distribution;

3) responsibility - the desire to help the buyer, service guarantee

4) completeness - the presence of the required skills, competence, knowledge;

5) accessibility - ease of establishing contacts with service providers, convenient time for the provision of logistics services for the buyer; 
6) security - there are no danger, risk, distrust (for example, the safety of cargo during transportation);

7) politeness - the behavior of the service provider, the correctness of the staff;

8) interpersonal skills - the ability to speak the language understood by the buyer;

9) mutual understanding with the buyer - a keen interest in the buyer, the ability to understand his needs (requirements).

The authors of this article adhere to the abovementioned structure of evaluating of the effectiveness of enterprise logistics and propose to attribute to the quality of the logistics service a purely segment of the transportation of finished products to the buyer.

In their work D.B. Bazhina and E.A. Koroleva [9] studied all of the above approaches and suggested the following methodology for assessing transport services:

1) there is classification into groups of all key indicators on transport processes: basic and private;

2) the list of basic indicators comprises following parameters: productivity, cost, reliability, timeline

3) the list of private indicators is based on the specifics of business organization, there number is unlimited, but is included in the list of basic indicators.

All basic indicators can be described as:

- $\quad$ performance: distance, speed, level of transport performance and handling charges;

- costs: costs for registration, transportation, storage cost, fines

- reliability: the probability of accidents, loss or damage to the goods, poor service, maintenance;

- timeline: handling charges, time for drafting of documents, time to strengthen the goods in transport.

\section{Internet of things in logistics service}

Today, the digitalization of the economy has a profound impact on various areas of business, including delivery logistics. The combination of mobile technology, cloud services and Big Data allows the transport and logistics process to move to a whole new level of quality using the Internet of Things technology [10].

The combination of mobile computing, analytics, and cloud services, all of which are powered by the Internet of Things (IoT), is changing how delivery and delivery companies perform their operations.

One of the main trends in the supply chain is asset controlling, which allows managers to reconsider their approach to logistics operations, providing information and leverage to make the right management decisions. [11,12] Two large companies, DHL and Cisco, considered that the introduction of technologies such as the Internet of Things to improve the organization's asset management function could have an impact on the entire logistics industry and supply chain of more than $\$ 1.9$ trillion. [13].

The function of controlling with the use of modern technology is no longer something new. For a long time, a bar- coding system has been introduced everywhere, which is becoming obsolete, since the use of the Internet of Things technology allows not only keeping records of goods, but also determining their location and state in real time [14].

To date, there is a list of new technologies that are already changing the work of logistics companies. First, there are active and passive RFID tags that provide data about the objects to which they are attached. The main difference between them is that the passive tags have an RFID antenna and a microchip for storing information, while the active tags have their own battery charge and can sometimes include additional sensors.

Internet-connected trackers use long-distance networks or Low-power Wide-area Network (LPWAN) to allow companies to track specific positions during their delivery. In the same vein, satellite trackers provide data on the location of an object almost anywhere in the world, even in areas where there is no cellular connection.

Bluetooth technologies offer tracking data in small areas and confined spaces. Companies most often use them in retail stores and shopping centers to monitor customer traffic and offer marketing messages to specified customers.

Finally, short-range radio tags (NFC), based on RFID standards, allow employees to use their smartphones as readers for NFC tags, which ensures the advantage of this technology due to convenience and accessibility over tags and other readers.

According to estimates by BI Intelligence, a research service of Business Insider, by 2020 the number of connected fleet management solutions will reach 180 million commercial vehicles in North America, or $90 \%$ of the total market share. This will be ten times more than in 2010. [13]

\section{RESULTS}

In connection with the recent significant increase in customer focus, many companies identify the level of perfect orders POF (Perfect Order Fulfilment) as a key indicator of transport logistics efficiency, since maintaining a high level of order execution service is one of the key factors for retaining and attracting customers, which can be both consignees and shippers. The index of a perfect order is often interpreted by companies as the three-factor model OTIFIC (On Time, In Full, Invoiced Correctly), which implies timely delivery, the order is complete and the accuracy of its execution, but the number of operations related to the characteristics of orders at each enterprise may be different. [14]

At the moment, most of the logistics operations are various kinds of services for customers of the enterprise, while the cost of these operations can occupy a significant share of the cost of production. Due to the fact that transactions are often carried out with the participation of logistics chain intermediaries - transport companies, forwarding brokers and traders, the issue of assessing the quality of transport services is more than relevant, because the efficiency of logistics counterparties has a critical effect on customer satisfaction and, therefore, on the effectiveness of the logistics chain of the enterprise as a whole. Taking into account the growth of the logistics outsourcing segment in Russia [15], the following list of indicators of the efficiency 
of transport services is proposed, which is partially based on the integrated order indicator.

As indicators of the efficiency of transport logistics and the quality of the company's logistics services within the framework of the balanced scorecard, the authors of this article propose to highlight the following indicators:

- number of customer complaints to the logistics service;

- timeliness of transport order;

- compliance with the loading / unloading interval;

- timeliness of submission of documents;

- timeliness of delivery;

Of course, within the specifics of the business of various companies, the set of indicators can and should be changed, however, the above indicators can be suitable as a template for creating a balanced scorecard of enterprise logistics.

As known, the controlling function in all respects is based on the collection and systematization of statistical data [1618]. However, these data may be distorted by employees due to personal motivation, or lack of necessary staff qualifications [19]. Against this background, IoT and RFID technologies are becoming increasingly popular in logistics, which are aimed at creating a unified digital space. Special attention of the logistics chain should be paid to the Internet of

Things for monitoring and communicating logistic service indicators that were previously problematic or completely impossible to obtain. The provided technologies help to significantly reduce the time between the receipt / processing of information and making the right management decision, which is critical when tracking the effectiveness of logistics [20]. In this way, there is a greater openness of the entire supply chain, and the reliability of information without human intervention is ensured. Due to the use of these technologies, the supply chain becomes more flexible, it becomes possible to take into account the preferences of customers, providing a higher level of service due to the openness and transparency of transportation.

In transport logistics today there are successful examples of the application of digital technologies using RFID, both for sea container transportation and for road transport. Each container or even a pallet is supplied with a telematic sensor, which transmits information about the current location of the cargo, its safety, environmental conditions among themselves using the MESH network, and then to the nearest transmitter. The latter, in turn, transmits data via mobile or satellite communications to the server. Thus, the cargo owner or consignee has the ability to track the location, safety and condition of the cargo or vehicle they need in real time, as well as determine the deadlines and stages of the transportation process.

Today's reality shows that even large Russian logistics companies are not able to fully incorporate digital technologies into their business processes. There are a number of problems in real-time cargo tracking within RFID technology:

- The problem of constant recharging. The fragility of telematics sensors is associated with a high degree of energy consumption, which is critical for delivery over 6 days.

- The problem of proper positioning. There is a risk of interruption or complete absence of a signal if the position is initially incorrectly positioned, or the positioning changes during transportation. This problem is observed during transportation of groupage cargoes, when the sensors need to be fixed on each loading unit, and not on the vehicle.

- The problem of creating the necessary infrastructure. When transmitting data using a cellular network, the possibility of no signal appears, which is especially noticeable in remote regions.

One of the stages of the widespread introduction of digital technologies in logistics is the creation of the necessary infrastructure, which is more entrusted to commercial enterprises than the state. An example is the development of various kinds of applications and business solutions for controlling the access of freight road transport to terminals or ports using cloud solutions or RFID tags at checkpoints.

\section{DISCUSSION AND CONCLUSIONS}

The modern world trend is the digitalization of society and business. The Internet of Things for transport logistics, in which objects of logistics or "things" are able to process information, communicate with each other and even make their own decisions are already becoming commonplace.

Today, only large commercial companies that use a huge number of vehicles in their business are increasingly using digital solutions to manage their own fleet of vehicles to make their business processes more efficient and cost-effective. However, the digitalization of business processes of companies is necessary only in determining a clear need for this. The introduction of a balanced scorecard and key performance indicators of an organization or a business unit defines the goals and sets the need for such technologies. Using the Internet of Things will help to achieve transparency at most stages of the supply chain, due to which the work will be aimed at greater efficiency, which will signal the list of selected indicators. Digitalization of business processes and a balanced scorecard determines the close relationship between the components of business processes, which is necessary for making effective management decisions.

The growth of connectivity allows logistics companies to have access to information not only consumers, but also all participants in the logistics chain. The development of digital technologies will allow even small companies to meet the growing demands of customers without the use of heavy investments, since the cost of these technologies is no longer so high. In turn, customers can rely on the flexibility of the logistics service, and most importantly on its reliability and openness. Taking into account the above, the use of the Internet of things technology as part of the overall digitalization of business processes is no longer just one of the competitive advantages, but simply a necessity in the rapidly developing transport and logistics services market.

Summing up, the technology of the Internet of Things in logistics allows to:

- monitor all processes in real time;

- determine people's productivity and 
make adjustments in the course of work toimprove it;

- $\quad$ automate the process and reduce the amount of manual work;

- $\quad$ optimize the process of joint work of workers, systems and assets;

- implement a more effective and innovative approach based on the data obtained;

- improve service quality and minimize risks in case of unforeseen circumstances.

The listed opportunities in integration with a correctly selected system of balanced scoreboard provide an opportunity for a significant increase in the efficiency of business processes and an improvement in the quality of transport and logistics services.

\section{REFERENCES}

[1] D. Parmenter - Key performance indicators. Development, implementation and application of crucial indicators. Moscow: Olymp- Business, 20053.

[2] R. Kaplan, D. Norton. . Balanced Scorecard. From strategy to action Moscow: Olimp-Business 2003 p. 23.

[3] R. Kaplan, D. Norton. Strategic maps. Transformation of intangible assets into tangible results. Moscow: Olimp-Business, 200529.

[4] E. N. Lopatina, D. E. Mitrofanov, A. A. Onuchina, Z. S. Prokhorov, E.

V. Shpak Improving the Organization's Management System in the Conditions of Changes [Text] // Economics and Practice: Materials VI International scientific conf. (Chita, April 2018). - Chita: Young Scientist Publishing House, 2018. - p. 29-32.

[5] K. V. Lepikhin, A. V. Kocheva, E. A. Skryabina Elements of a New Organization Management System // Vestnik of the Perm State Humanitarian-Pedagogical University. 2016. No. 1. P. 24-29.

[6] Sergeev. IN AND. Key performance indicators of logistics // Financial Director 2011 №5 in. 36 - 40

[7] Lukinsky V.V., Shulzhenko T.G. Evaluation of the effectiveness of the company's logistics activities based on key indicators // Audit and financial analysis. №4, 2011, p. 1-7.

[8] Key performance indicators of logistics // [Electronic resource]. URL: http://www.elitarium.ru/logistika-gruzoperevozki-transportperevozka-gruzov-uslugi-proizvoditelnost/ (appeal date04/16/2019).

[9] Bazhina D.B. Koroleva E.A. Development of key performance indicators of transport services // Logistics and supply chain management. 2018 №5 p. 46-52.
[10] Logistics [Electronic resource]: online course / Dubolazov V.A., Simakova Z.L. and etc .; St. Petersburg Polytechnic University of Peter the Great, - [St. Petersburg, 2016]. URL: https://openedu.ru/course/spbstu/LOGIST/.

[11] Gutman, S.S., Zaychenko, I.M., Rytova, E.V. Development strategy of Far North transport infrastructure: Problems and prospects (2017) pp. 1439-1449.

[12] Ilin, I., Kalinina, O., Iliashenko, O., Levina, A. Sustainable Urban Development as a Driver of Safety System Development of the Urban Underground (2016) Procedia Engineering, 165, pp. 1673-1682.

[13] How IoT logistics will revolutionize supply chain management // [Electronic resource].

URL: https://www.businessinsider.com/internet-of-things-logisticssupply- chain-management-201610 ?utm_source $=$ datafloq\&utm_medium $=$ ref\&utm_campaign $=$ datafl o q\&I / (appeal date 16.04.2019).

[14] Levina A.I., Dubgorn A.S., Ilyashenko O.Yu. The Internet of Things in the Service Architecture of Intelligent Transport Systems (2018) Proceedings - 2017 European Conference on Electrical Engineering and Computer Science, EECS 2017, p. 351-355.

[15] The market of logistics outsourcing: the results of 2017-2018 and the forecast until 2022 // [Electronic resource]. URL: https://maresearch.ru/novosti-issledovanij/item/207-v-2019-godu-tempy-rostarynka-transportno-logisticheskikh-uslug-snizyatsya-do-3-3-privysokom- Riske-vkhozhdeniya-v-retsessiyu.html

[16] Ilin, I.V., Iliashenko, O.Yu., Borremans, A.D. Analysis of cloudbased tools adaptation possibility within the software development projects (2017) 2017-January, pp. 2729-2739.

[17] Efimov, V.V., Mescheryakov, S.V., Shchemelinin, D.A. Integration data model for continuous service delivery in cloud computing system (2017) 700, pp. 87-97.

[18] Klimin, A.I., Pavlov, N.V., Efimov, A.M., Simakova, Z.L. Forecasting the development of big data technologies in the Russian Federation on the basis of expert assessments (2018) pp. 1669-1679.

[19] Ilin, I.V., Iliashenko, O.Y., Klimin, A.I., Makov, K.M. Big data processing in Russian transport industry (2018) pp. 1967-1971.

[20] V.K. Potyomkin SPSUEF: A Look into the Past and the Present // Izvestiya SPbGEU. 2010. №4. From 163-169.

[21] B. Karakostas. DNS architecture for the Internet of things: a case study in the field of transport logistics. Computer Science, Volume 19, 2013, p. 594-601. 